\title{
Mechanical Properties of the Wood-Based X-Type Lattice Sandwich Structure
}

\author{
Tengteng Zheng, Yanpeng Cheng, Shuai Li, Yan Zhang, and Yingcheng $\mathrm{Hu} *$ \\ In this study, a wood-based X-type lattice sandwich structure was \\ fabricated by an insertion glue method using medium density fiberboard \\ (MDF) and plywood as panels. Birch was used for the core. The \\ mechanical properties and failure modes of the wood-based X-type lattice \\ sandwich structure were investigated by an out-of-plane compressive \\ test, a short beam shear test, and their matching analytical models. The \\ out-of-plane compressive test and the compression analytical model \\ showed that the failure mode of the plywood and birch combination was \\ mainly shear failure in the core. The cores were broken or had sliding \\ surfaces, while the failure mode of the MDF and birch combination was \\ mainly shear failure of the core at both ends. Although the compression \\ properties of the MDF and birch combination were better, the specific \\ strength and modulus of the plywood and birch combination was larger, \\ which align with the characteristics of lightweight and strong strength. The \\ failure mode of the plywood and birch combination was delamination at \\ both ends of the panel or core breakage, which indicated that this \\ combination had better short beam shear properties. The theoretical \\ models of the compressive /short beam shear properties were in good \\ agreement with experimental results obtained for the plywood and birch \\ combination.
}

Keywords: Wood composite; X-type; Lattice sandwich structure; Mechanical properties; Failure modes

Contact information: Key Laboratory of Bio-based Material Science and Technology of Ministry of Education of China, College of Material Science and Engineering, Northeast Forestry University, Harbin 150040, China; *Corresponding author: yingchenghu@nefu.edu.cn

\section{INTRODUCTION}

Wood is one of the four major building materials in the world. The others are steel, cement, and plastic. Compared with other building materials, wood has outstanding thermal insulation, a high ratio of strength to weight, environmental protection properties, and others. It creates an elegant and natural living environment and improves mental health (Profft et al. 2009; Healy et al. 2018; Hu et al. 2018; Kržišnik et al. 2019; Munir et al. 2019). However, the wood itself is easily deformed, susceptible to shrinkage and humidity, decomposes easily, burns easily, and high-quality wood has been over-harvested. At present, natural forest resources have been excessively logged, and the remaining forest resources are mostly used to protect soil erosion and maintain ecological balance. Therefore, low quality wood such as artificial fast-growing plantation forest has become the main source of commercial wood. The emphasis of processing and utilization in the future is the deep development and high value-added utilization of the advanced technologies of artificial fast-growing forest and processing residues. As environmental issues become more prevalent, research on composite materials based on renewable resources have been gaining popularity. The preparation and application of wood-based 
composites, especially wood engineering materials, have great advantages for realizing the use of inferior wood and improving the utilization rate of wood resources (Ashby et al. 2001; Evans 2001; Irle et al. 2019; Jamalirad et al. 2019).

The lattice sandwich structure is a kind of truss structure that is composed of rigid thin panels and cores. The mechanical properties are easy to predict, and the mechanical properties in various aspects are much better than those of foam materials (Ashby et al. 2000; Bunyawanichakul et al. 2008; Pandit et al. 2018; Garg and Chalak 2019). Most lattice sandwich structures are made of metals, fiber reinforced materials, and composites (Giancaspro et al. 2006; Mahmut 2014; Mathieson and Fam 2015; Li et al. 2019), and the mechanical properties of different lattice sandwich structures are different (Deshpande et al. 2001). Yin et al. $(2012,2011,2013)$ studied the properties of carbon fiber (CF) composite pyramidal lattice (CPL) structures filled with wood and silicone rubber. Their results showed that the energy absorption capability was enhanced for the rubber-core truss CPL, and the density-specific performance space of the CF composite lattice structures can be expanded by employing the hybrid truss construction. Wang et al. (2010, 2011, 2013, $2014,2014,2018$ ) studied the mechanical properties of the pyramidal and the X-type lattice sandwich structure. Their results showed that the mechanical properties of the X-type lattice sandwich structure were better than those of the other pyramidal sandwich structures.

Lattice sandwich structures prepared with metal materials as matrix composites have been gradually applied in large aerospace spacecraft and other fields (Li et al. 2003; Jiang et al. 2011; Liu et al. 2015). However, there have been few studies on lattice sandwich structures composed mainly of wood or wood composite materials, which are worth exploring as wood engineering materials in wood structure buildings (Karam et al. 1994; Way et al. 2016). Li et al. $(2018,2019)$ studied the effects of the optimized core on the compressive behavior of the bio-based two-dimensional (2-D) lattice structure. Their results showed that the optimized bio-based 2-D lattice structure had superior mechanical properties compared to other biomaterials. Jin et al. (2015) studied the mechanical properties of wood-based 2-D lattice truss core sandwich structures composed of different panel materials. Their results showed that the failure mode of the structure was shear failure, and the lattice core sandwich structures had good energy absorption capability.

Absorption capability is an important factor for the safety of wooden construction. Qin et al. (2019) examined the effects of the core configuration on the out-of-plane compressive behavior of a wood-based 2-D straight column lattice truss sandwich structure. Their results showed that the ultimate strength in the out-of-plane compression of the eight different configurations followed a linear relationship with the relative density of the core.

Using a wood composite material as a lattice structure not only improves the utilization of natural resources, but it also is environmentally friendly. Using filling functional materials in a wood-based lattice sandwich structure can realize the integration of the structure and function (Xu et al. 2017; Liu et al. 2019). The study of the mechanical properties of a wood-based X-type lattice sandwich structure as a new configuration is particularly important for obtaining its light weight, high strength, and multi-function integration. 


\section{EXPERIMENTAL}

\section{Materials}

Plywood (Lixiang Enterprise Co. Ltd., Shanghai, China) and MDF (Xiaomei Wood Industry Co. Ltd., Shanghai, China) were used as panel materials, and the birch (Tengzhan Wood Industry Co. Ltd., Harbin, China) was used as core materials. Epoxy resin (Type: WSR6101 E-44) was purchased from Star Synthetic Materials Co. LTD (Nantong, China). Polyamide resin (Type: Low molecular-650-) was purchased from Danbao Resin Co. LTD (Chuzhou, China). The mechanical properties of the core materials are shown in Table 1.

Table 1. Mechanical Properties of the Core Materials

\begin{tabular}{|c|c|c|c|c|c|}
\hline Type & $\rho\left(\mathrm{g}^{\prime} \times \mathrm{cm}^{-3}\right)$ & $L(\mathrm{~mm})$ & $d(\mathrm{~mm})$ & $\begin{array}{c}\text { Compressive } \\
\text { strength (MPa) }\end{array}$ & $\begin{array}{c}\text { Compressive } \\
\text { modulus }(\mathrm{GPa})\end{array}$ \\
\hline \multirow{2}{*}{ Birch } & \multirow{2}{*}{0.57} & 60 & 6 & 41.12 & 2.26 \\
\cline { 3 - 6 } & & 60 & 8 & 52.37 & 2.94 \\
\hline \multirow{2}{*}{ GFRP } & \multirow{2}{*}{1.87} & 60 & 6 & 368.05 & 25.91 \\
\cline { 3 - 6 } & & 60 & 8 & 378.95 & 21.30 \\
\hline
\end{tabular}

(a)

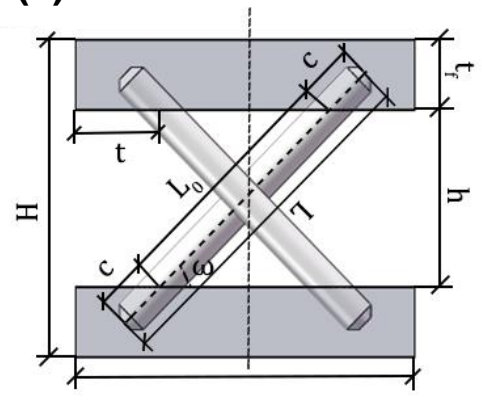

(b)

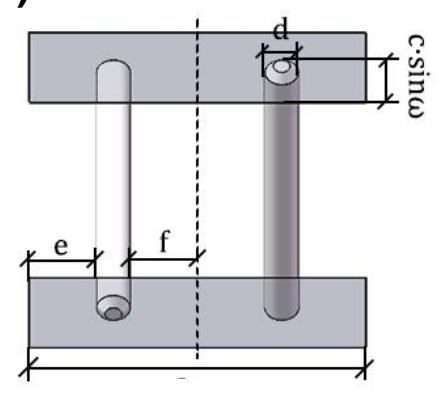

(c)

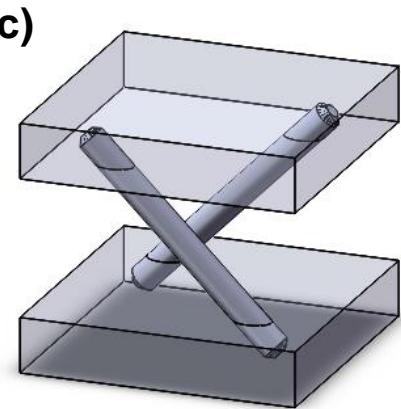

Fig. 1. The unit cell schematic of the X-type lattice sandwich structure (a) main view, (b) side view, (c) three-dimensional diagram

\section{Methods}

Cell size design

The unit cell schematic of the X-type lattice sandwich structure is shown in Fig. 1, and the relative density of the X-type lattice sandwich structure was calculated as follows,

$$
\begin{aligned}
& \bar{\rho}=\frac{\pi d^{2} L_{0}}{4 a\left(L_{0}+2 t\right)} \\
& a=2(e+f)
\end{aligned}
$$




$$
\begin{aligned}
& b=L_{0} \cos \omega+2 t \\
& L_{0}=L-2 c
\end{aligned}
$$

where $L$ and $d$ are the length and diameter of the core, whereas $b, a$, and $t_{\mathrm{f}}$ are the length, width, and thickness of the panel, respectively. The parameter $c$ is the depth of the punching, $t$ is the distance from the drilling position to the nearest edge of the panel, and $\omega$ is the angle of the core and panel. The parameter $e$ is the distance from the drilling position to the nearest edge and $f$ is the distance from the center line, and $L_{0}$ is the length of the core in the core layer.

\section{Manufacturing process of the X-type lattice sandwich structure}

In the manufacturing process of the wood-based X-type lattice sandwich structure (Fig. 2), the panels and cores of the required size were cut. The upper and lower panels were drilled with the required size bit at the required angle. The appropriate mixture of epoxy resin and polyamide resin was added into the holes of the panel. The cores were inserted into the holes of the panel. Lastly, the suitable pressure was applied on the lattice structure with a horizontal tong. The specimens were removed from the horizontal tong after $72 \mathrm{~h}$, and the fabrication of the X-type lattice sandwich structure was completed.

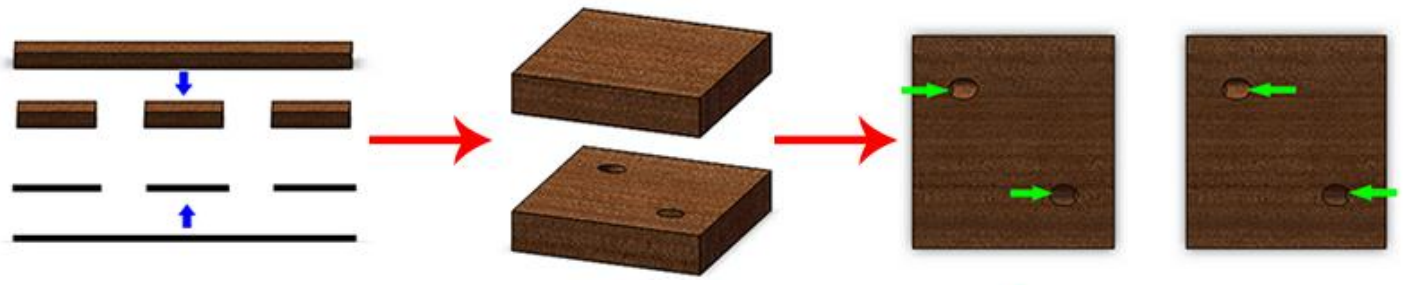

(a) Sawing

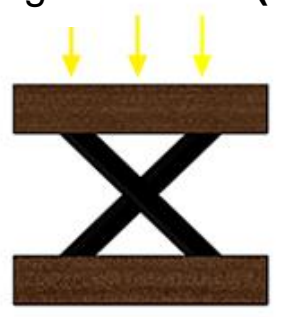

(b) Drilling hole

(c) Sizing

(e) Pressing and letting it down

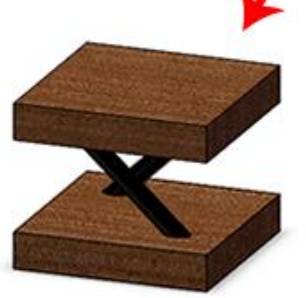

(d) Assembly

Fig. 2. The manufacturing process of the X-type lattice sandwich structure

\section{Out-of-plane compression test}

According to the ASTM C365/C365M-16 (2016) standard test method for compression strength and modulus, the X-type lattice sandwich structure was tested at room temperature using a universal ability test machine (C61.104, Shenzhen, China), at a displacement rate of $1 \mathrm{~mm} / \mathrm{min}$, and the experimental apparatus is depicted in Fig. 4(a). The load-displacement curve of the structure was based on the measured load and displacement. The compression tests of one type of specimen (X-type) were separately conducted with two kinds of combinations. The parameters of the X-type lattice sandwich structure for out-of-plane compression are shown in Table 2.

Equation 5 was used to calculate the compressive strength,

$$
\sigma_{c}=P_{\max } \div(b \times l)
$$


where $P_{\max }$ is the maximum compressive load, $b$ is the width, and $l$ is the length of the compression test specimen.

Equation 6 was used to calculate the compressive modulus,

$$
E_{c}=(\Delta P \times h) \div(l \times b \times \Delta h)
$$

where $\Delta P$ is the load increment of the linear elastic part of the compressive curve, $\Delta h$ is the compressive deformation increment corresponding with $\Delta P$, and $h$ is the thickness of the compression test specimen.

Table 2. Cell Size Design of the Compression Test

\begin{tabular}{|c|c|c|c|c|c|c|c|c|}
\hline Group & Type & Materials & $\begin{array}{c}a \\
(\mathrm{~mm})\end{array}$ & $\begin{array}{c}b \\
(\mathrm{~mm})\end{array}$ & $\begin{array}{c}d \\
(\mathrm{~mm})\end{array}$ & $\begin{array}{c}t_{f} \\
(\mathrm{~mm})\end{array}$ & $\begin{array}{c}L \\
(\mathrm{~mm})\end{array}$ & $\begin{array}{c}\bar{\rho} \\
(\%)\end{array}$ \\
\hline 1 & $\mathrm{X}$ & $\begin{array}{c}\text { Plywood and } \\
\text { birch }\end{array}$ & 60 & 60 & 6 & 12 & 60 & 1.11 \\
\hline 2 & $\mathrm{X}$ & MDF and birch & 60 & 60 & 6 & 12 & 60 & 1.11 \\
\hline 3 & $\mathrm{X}$ & $\begin{array}{c}\text { Plywood and } \\
\text { birch }\end{array}$ & 60 & 60 & 8 & 12 & 60 & 1.97 \\
\hline 4 & $\mathrm{X}$ & MDF and birch & 60 & 60 & 8 & 12 & 60 & 1.97 \\
\hline
\end{tabular}

*(1) Plywood and birch denotes the combination of plywood as the panel and birch as the core, and MDF and birch denotes the combination of MDF as the panel and birch as the core.

(2) Plywood is an anisotropic material and its mechanical properties are the best along the direction of the shaving, so the projection direction of the core in the combination of plywood and birch is parallel to the direction of the shaving of plywood.

\section{Short beam shear test}

The short beam shear test of the X-type lattice sandwich structure was conducted according to the ASTM C393/C393M-16 (2016) standard, using a universal ability test machine at a loading rate of $0.5 \mathrm{~mm} / \mathrm{min}$. The device for the short beam shear test is shown in Fig. 4(b). Two types of specimens, namely $\mathrm{X}(\mathrm{V})$-type and $\mathrm{X}(\mathrm{H})$-type, were tested by the short beam shear test (Fig. 3). The parameters of the X-type lattice sandwich structure for the short beam shear test are shown in Table 3. The short beam shear test load-displacement curve can be obtained based on the measured load and displacement.

The shear stress of the core was calculated as follows,

$$
\tau_{c}=(P \times K) \div\left(2 b\left(h-t_{f}\right)\right)
$$

where $P$ is the midspan load, $K$ is dimensionless (its value is 1 ), $b$ and $h$ are respectively the width and thickness of the specimen, and $t_{f}$ is the thickness of the panel. Equation 8 was used to calculate the shear stiffness of the structure,

$$
\mathrm{U}=\frac{l \cdot \Delta P}{4\left(f-\frac{1}{3 e} \times f_{1}\right)}
$$

where $\Delta P$ is the load increment of the load-deflection curve at the initial elastic stage, $f$ is the deflection increment of the corresponding $\Delta P$ in the span of the structure, $e$ represents the extended arm length, and $f_{l}$ is the increment of deflection at the extension point of $\Delta P$ (taking the average of the left and right points).

The following equation was used to calculate the shear modulus of the core,

$$
G_{c}=U \div\left(b\left(h-t_{f}\right)\right)
$$

where $G_{c}$ represents the shear modulus of the core, $U$ represents the shear stiffness of the structure. 


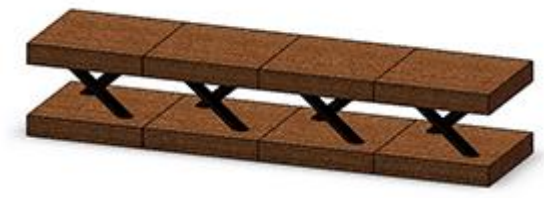

(a) X(V)-type

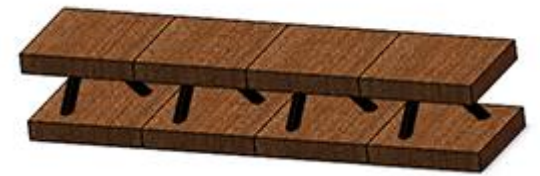

(b) $\mathrm{X}(\mathrm{H})$-type

Fig. 3. Short beam shear specimens tested

Table 3. Size and Design of the Short Beam Shear Test

\begin{tabular}{|c|c|c|c|c|c|c|}
\hline Group & Type & Materials & $L_{f}(\mathrm{~mm})$ & $B(\mathrm{~mm})$ & $d(\mathrm{~mm})$ & $L(\mathrm{~mm})$ \\
\hline 1 & $\mathrm{X}(\mathrm{V})$ & Plywood and birch & 240 & 60 & $6 / 8$ & 120 \\
\hline 2 & $\mathrm{X}(\mathrm{V})$ & MDF and birch & 240 & 60 & $6 / 8$ & 120 \\
\hline 3 & $\mathrm{X}(\mathrm{H})$ & Plywood and birch & 240 & 60 & $6 / 8$ & 120 \\
\hline 4 & $\mathrm{X}(\mathrm{H})$ & MDF and birch & 240 & 60 & $6 / 8$ & 120 \\
\hline
\end{tabular}

(a)

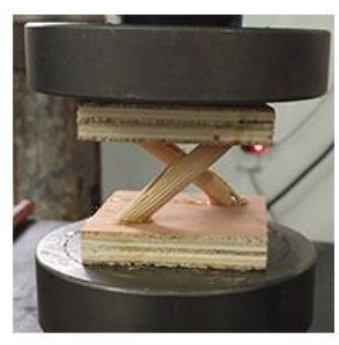

(b)

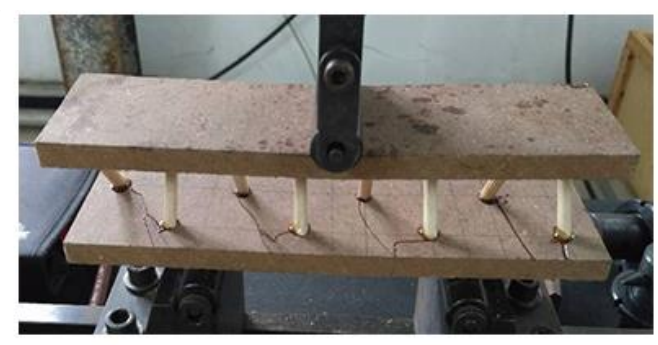

Fig. 4. The experimental apparatus: (a) compression test and (b) short beam shear test

Theoretical model of compressive property

To predict the mechanical properties of the wood-based X-type lattice sandwich structure, analytical models for the compressive and short beam shear properties of the Xtype lattice sandwich structure were derived according to the methods proposed by Wang and others (Manalo 2013; Li et al. 2018; Wang et al. 2018).

The hypothetical premise is that the two ends of the core are fixed on the panel. It was assumed that there was no relative slip or slip surface between the core and the upper and lower panels under the compressive load. The deformation of the X-type lattice sandwich structure is shown in Fig. 5(a). The force formula of the upper panel was in the horizontal state, assuming that the longitudinal displacement of the upper part of the core is $\delta$ and the transverse displacement and rotation angle of the core is zero (Fig. 5(b) and Fig. 5(c)). The upper end of the core could only move downward under the compressive load, where the theoretical load capacity was decomposed into the axial force and the transverse shear force.

The axial force and transverse shear force of the core can be expressed by Eq. 10 and Eq. 11,

$$
\begin{aligned}
& \mathrm{F}_{\mathrm{N}}=\left(\pi d^{2} \times E_{c} \times \delta \sin \omega\right) \div 4 L_{0} \\
& \mathrm{~F}_{\mathrm{s}}=\left(12 \times E_{c} \times l \delta \cos \omega\right) \div \mathrm{L}^{3}
\end{aligned}
$$


where $F_{\mathrm{N}}$ and $F_{\mathrm{s}}$ are, respectively, the axial force and transverse shear force of the core, $E_{c}$ is the compression modulus of the core, $\omega$ is the angle of the core and panel, $\delta$ is the vertical compressive displacement of the lattice structure, $L_{0}$ is the length of the core in the core layer.

The load capacity is given by Eq. 12,

$$
F=F_{N} \sin \omega+F_{S} \cos \omega=\frac{\pi d^{2} E_{C} \delta}{2 L_{0}}\left[\sin ^{2} \omega+\frac{3}{4}\left(\frac{d}{L_{0}}\right)^{2} \cos ^{2} \omega\right]
$$

where $I$ is the moment of inertia of the core.

The strain of the X-type lattice sandwich structure can be expressed by Eq. 13,

$$
\varepsilon=\delta \div\left(L_{0} \sin \omega\right)
$$

where $\varepsilon$ is the strain of the sandwich structure. The equivalent compressive strength and modulus were calculated according to Eqs. 14 and Eq. 15,

$$
\begin{aligned}
& \sigma=\frac{\pi d^{2} E_{C} \delta}{2 A L_{0}}\left[\sin ^{2} \omega+\frac{3}{4}\left(\frac{d}{L_{0}}\right)^{2} \cos ^{2} \omega\right] \\
& E=\frac{\pi d^{2} E_{C} \sin \omega}{2 A}\left[\sin ^{2} \omega+\frac{3}{4}\left(\frac{d}{L_{0}}\right)^{2} \cos ^{2} \omega\right]
\end{aligned}
$$

where $\sigma$ and $E$ are respectively the equivalent compressive strength and modulus, and $A$ is the cross sectional area of the core.

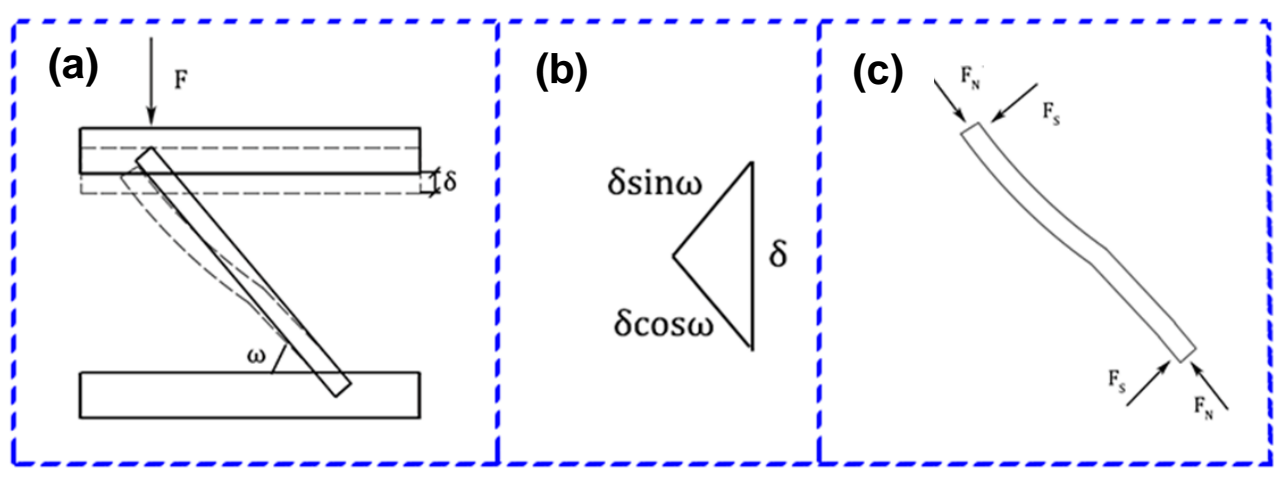

Fig. 5. (a) Lattice structure deformation, (b) displacement decomposition, and (c) core load situation

\section{Theoretical model of short beam shear property}

Under a three-point bending load, the upper and lower panels of the X-type lattice sandwich structure mainly bear bending loads, while the middle core mainly bears a shear load. As the core is a typical tensile dominant material, the rods in the core resist the external load mainly by compression deformation. Equation 16 was used to calculated the transverse shear modulus of the sandwich structure,

$$
G_{c}=\tau_{c} \div \gamma_{c}
$$

where $\tau_{c}$ is the transverse shear load of the core, and $\gamma_{c}$ is the transverse shear strain of the core. 
The transverse shear load and the transverse shear strain of the core were calculated according to Eqs. 17 and 18, and the axial force on the core was calculated according to Eq. 19.

$$
\begin{aligned}
& \tau_{c}=F_{A} \sin \omega \div b h \\
& \gamma_{c}=\Delta \div L_{0} \cos \omega \\
& F_{A}=\left(E_{c} \pi r^{2}\right) \times\left(\Delta \sin \omega \div L_{0}\right)
\end{aligned}
$$

where $\Delta$ is the midspan displacement of the force, and $F_{A}$ is axial force on the core.

The transverse shear modulus of core was calculated according to Eq. 20,

$$
G_{c}=\left(E_{c} \times \pi r^{2} \times \sin \omega \cos \omega\right) \div\left(b L_{0}\right)
$$

where $G_{c}$ is the transverse shear modulus of core.

\section{RESULTS AND DISCUSSION}

\section{Compression Failure Modes}

The load-displacement curves of the two types of the X-type lattice sandwich structures under compressive loading are shown in Fig. 6. These load-displacement curves are roughly divided into three stages, namely the elastic stage, the yield stage, and the descending stage after the peak load. In the elastic stage, the curve rises the most rapidly, and the structure has no obvious change. In the yield stage, the structure begins to deform and the adhesive layer cracks obviously. As the load increases, the rise rate of the curve will slow down until it reaches the peak and starts to decline. In this process, the deformation of the structure becomes larger and is gradually crushed.

(a)

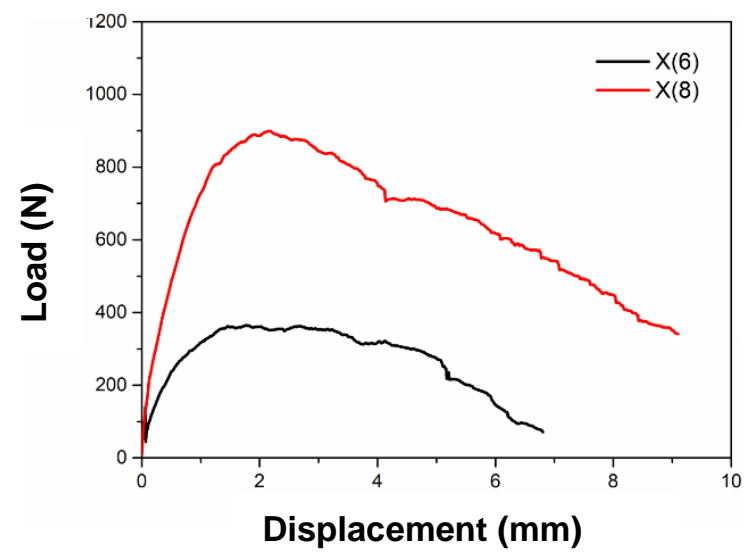

(b)

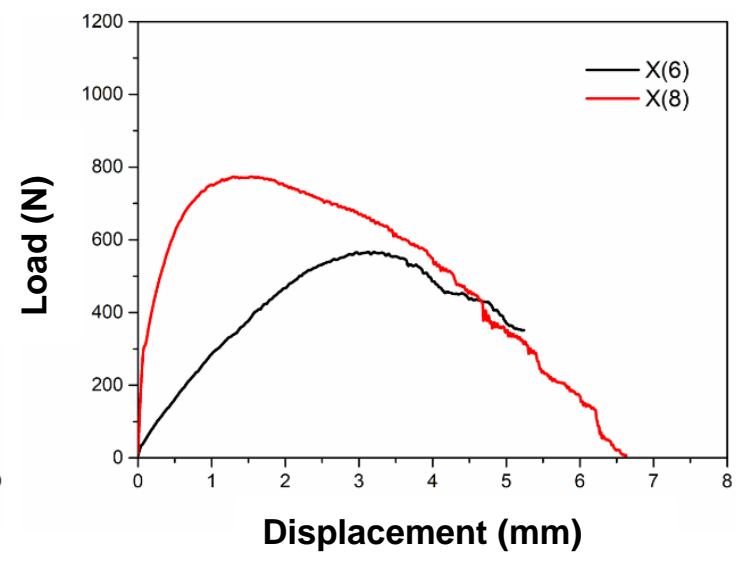

Fig. 6. Compression load-displacement curves of the two types of X-type lattice sandwich structures (a) Plywood and birch, (b) MDF and birch

The load-displacement curves of the plywood and birch combination are shown in Fig. 6(a). The main failure mode was shown to be core shear failure and the cores were broken or had sliding surfaces (Fig. 7(a)). The load-displacement curves of the X-type lattice sandwich structure with a core diameter of $8 \mathrm{~mm}$ was above that of the X-type lattice sandwich structure with a core diameter of $6 \mathrm{~mm}$. This is because the cores provide the 
main load capacity. With the increase of the compression load, the core will be completely broken. A thinner core results in a faster and more severe break.

The load-displacement curves of the combination of MDF and birch are shown in Fig. 6(b). The main failure mode was shear failure of the cores at the two ends, as shown in Fig. 7(b). The load capacity of the structure provided by the thick core is larger than that provided by the thin core.

(a)

(b)
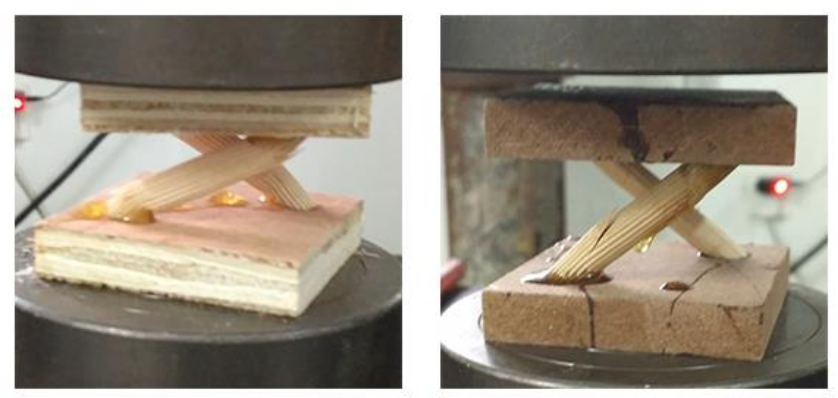

Fig. 7. Compression failure modes of the two types of X-type lattice sandwich structures (a) plywood and birch and (b) MDF and birch

\section{Compression Property}

High quality structural materials should have high specific strength to meet the strength requirements with the smallest cross-section possible, and at the same time they can greatly reduce the weight of the structure itself. Specific strength is the strength of a material (force per unit area at break) divided by its apparent density.

For the combination of plywood and birch, the load capacity (Fig. 8(a)), compressive strength (Fig. 8(b)), and compression modulus (Fig. 9(c)) of the X-type lattice sandwich structure with a core diameter of $8 \mathrm{~mm}$ were $85.38,81.82$, and $313.06 \%$ larger, respectively, than those of the X-type lattice sandwich structure with a core diameter of 6 $\mathrm{mm}$. The core provides load capacity for the structure and core with diameter of $6 \mathrm{~mm}$ is easy to break. The compressive strength and compressive modulus of the X-type lattice sandwich structure are positively correlated with the core diameter.

For the combination of MDF and birch, the load capacity (Fig. 8(a)), compressive strength (Fig. 8(b)), and compression modulus (Fig. 9(c)) of the X-type lattice sandwich structure with a core diameter of $8 \mathrm{~mm}$ were 10.67, 15.79, and 79.26\% larger than those of the X-type lattice sandwich structure with a core diameter of $6 \mathrm{~mm}$, respectively. The compression property of the structure with the size of the two cores has little difference, which indicates that the diameter of the cores has little influence on the compression performance of the structure, and the panel plays an important role in the structure.

With the same core diameter, the combination of MDF and birch has better compression performance than the structure of the plywood and birch combination, which load capacity, compressive strength, and the compression modulus are generally high.

For the combination of plywood and birch, the specific strength (Fig. 8(d)) of the X-type lattice sandwich structure with a core diameter of $8 \mathrm{~mm}$ was $79.26 \%$ larger than those of the X-type lattice sandwich structure with a core diameter of $6 \mathrm{~mm}$. This is because the weight of the panel is lighter. The diameter of the core determines the quality of the structure. The compression strength of the two core diameters varied greatly, so the specific strength of the X-type lattice sandwich structure with a core diameter of $8 \mathrm{~mm}$ was higher. 
(a)

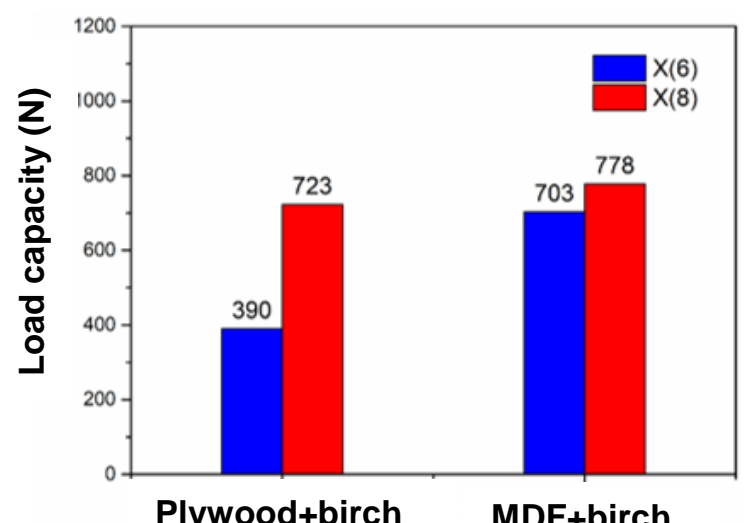

(c)

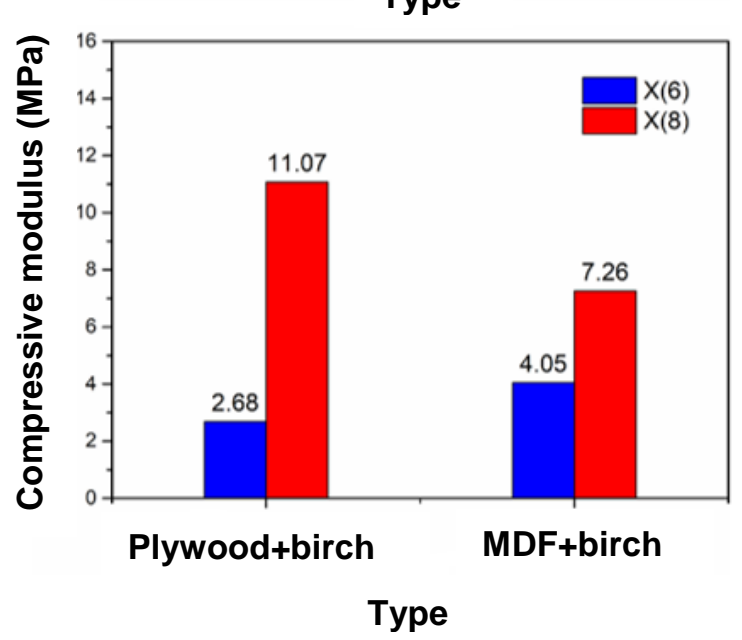

(b)

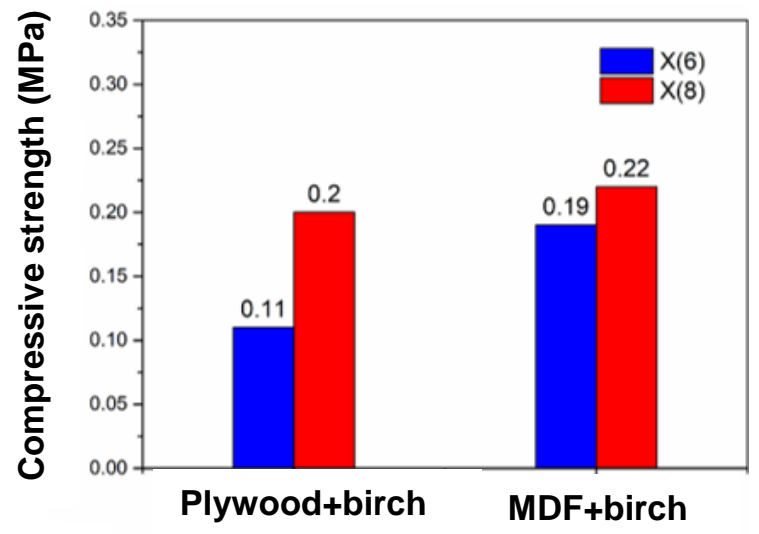

(d)

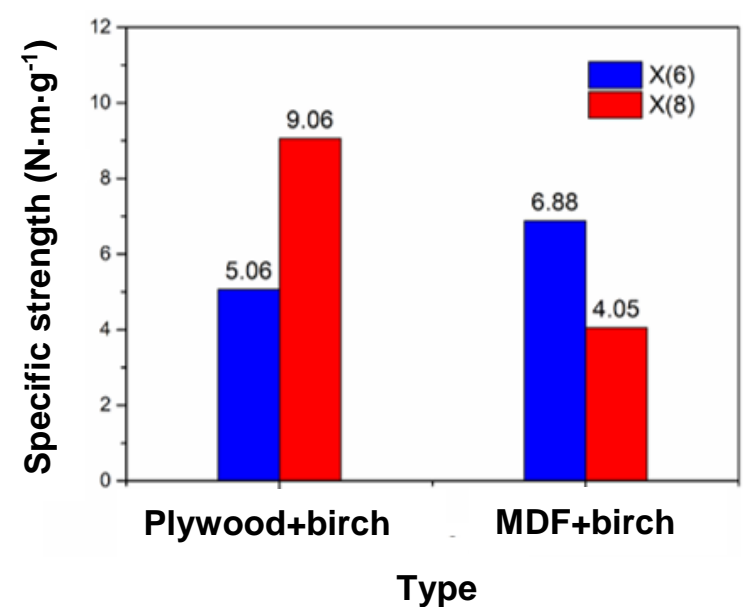

Fig. 8. (a) Load capacity, (b) compressive strength, (c) compression modulus, (d) specific strength of the two types of X-type lattice sandwich structures

For the combination of MDF and birch, the specific strength (Fig. 8(d)) of the Xtype lattice sandwich structure with a core diameter of $8 \mathrm{~mm}$ was $41.13 \%$ less than those of the X-type lattice sandwich structure with a core diameter of $6 \mathrm{~mm}$. This was due to the large mass of the panel and the relatively small mass of the structure with a core diameter of $6 \mathrm{~mm}$. Comparing the specific strength of the two combinations showed that the specific strength of the combination of plywood and birch was larger overall, which is in line with the characteristics of light weight and high strength.

\section{Short Beam Shear Failure Modes}

In order to explore the influence of the core and panel on the mechanical properties of the X-type lattice sandwich structure, the short beam shear tests of the combination of plywood and birch and MDF and birch were conducted.

The load-displacement curves of the combination of plywood and birch are shown in Figs. 9(a) and 9(b). Under the effect of loads, the sandwich structure enters the linear elastic stage, and the midspan displacement increases rapidly and evenly with the increase of the loads during this stage. The curve is serrated near the maximum value, which is the phenomenon of cracking in the adhesive layer. The main failure mode of the X(V)-type lattice sandwich structure is that the middle of the lower panel breaks off and the upper panel is layered at both ends (Fig. 10). The main failure mode of the $\mathrm{X}(\mathrm{H})$-type lattice 
sandwich structure is in the lamination of the panel and the core breaks off (structure with a core diameter of $6 \mathrm{~mm}$ ).

(a)

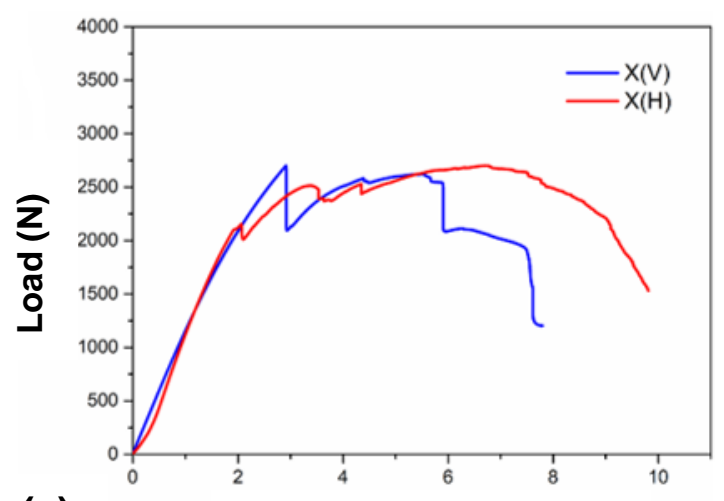

(c)

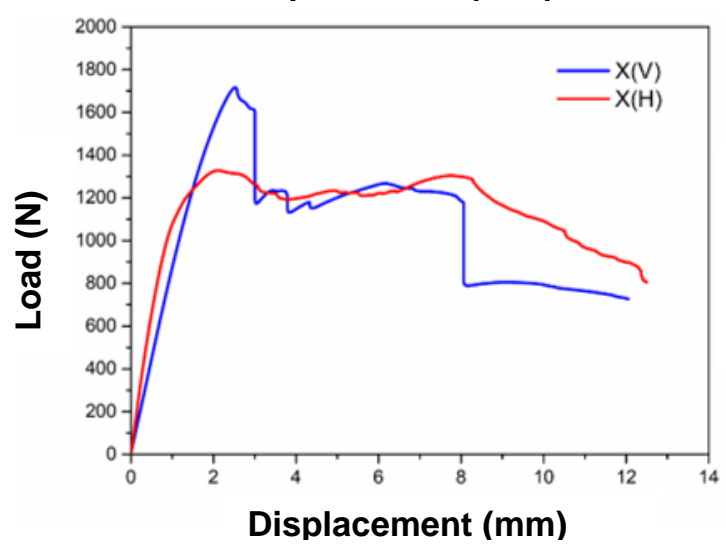

(b)

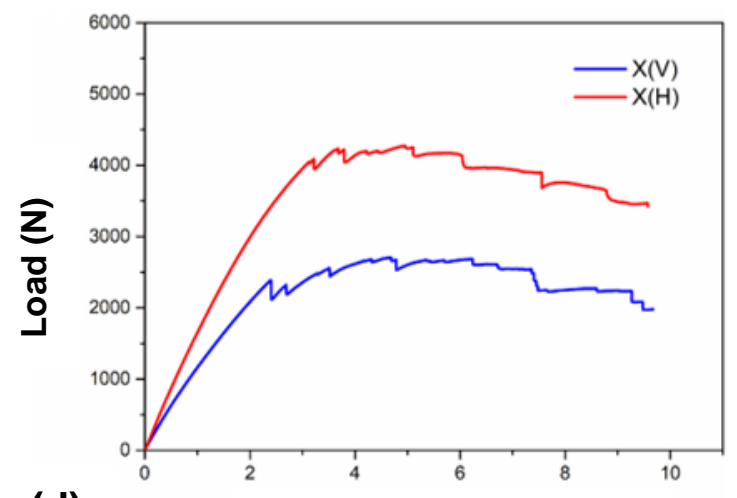

(d)

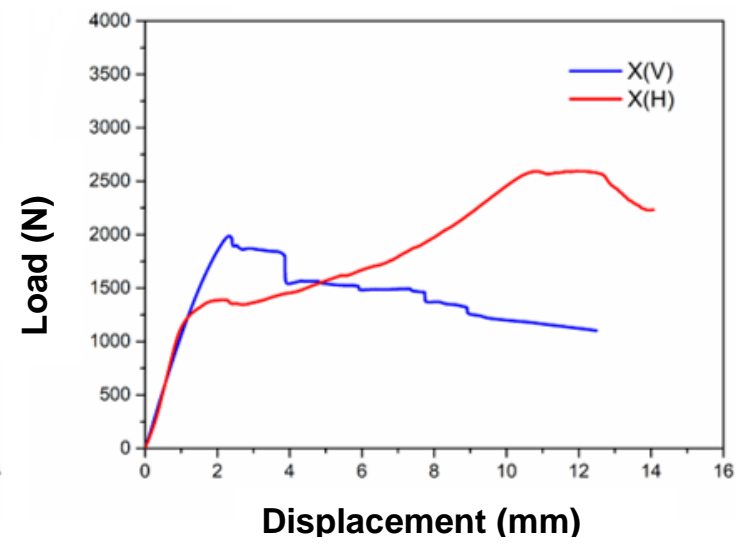

Fig. 9. Short beam shear load-displacement curves of the two types of $X$-type lattice sandwich structures (a) Plywood and birch (6), (b) Plywood and birch (8), (c) MDF and birch (6) and (d) MDF and birch (8). Plywood and birch (6) denotes the combination of plywood and birch with a core diameter of $6 \mathrm{~mm}$, plywood and birch (8) denotes the combination of plywood and birch with a core diameter of $8 \mathrm{~mm}$, MDF and birch (6) denotes the combination of MDF and birch with a core diameter of $6 \mathrm{~mm}$, and MDF and birch (8) denotes the combination of MDF and birch with a core diameter of $8 \mathrm{~mm}$.

The load-displacement curves of the MDF and combination are shown in Figs. 9(c) and $9(\mathrm{~d})$. The curve reveals a good linear relationship during the linear elastic stage. With the increase of the displacement, the rate of load increase decreases until the peak load is reached. After crossing the peak load, the curve decreases rapidly, and then there is a long plateau area. The main failure mode of the $\mathrm{X}(\mathrm{V})$-type lattice sandwich structure is the delamination of the panel at the loading point (Fig. 10), and the main failure mode of the $\mathrm{X}(\mathrm{H})$-type lattice sandwich structure is panel wrinkling and core shear failure.

\section{Short Beam Shear Property}

For the plywood and birch combination, the shear stress and modulus of the core of the $\mathrm{X}(\mathrm{V})$-type lattice sandwich structure with a core diameter of $6 \mathrm{~mm}$ were 1.92 and $57.7 \%$ larger than those of the $\mathrm{X}(\mathrm{H})$-type lattice sandwich structure (Figs. 11(a) and 11(b)). The shear stress and modulus of the core of the $\mathrm{X}(\mathrm{H})$-type lattice sandwich structure with a core diameter of $8 \mathrm{~mm}$ were 57.7 and $116.7 \%$ larger than those of the $\mathrm{X}(\mathrm{V})$-type lattice 
sandwich structure. This is because the core direction of the $\mathrm{X}(\mathrm{H})$-type lattice sandwich structure is perpendicular to the particleboard direction, while the core direction of the $\mathrm{X}(\mathrm{V})$-type lattice sandwich structure is parallel to the particleboard direction, which provides greater binding force. When the core diameter is $6 \mathrm{~mm}$, the core will fail in shear and be broken. The direction of the core has little effect on the shear stress and modulus of the core. Under the same configuration, a larger diameter results in better shear properties and flexural strength of the structure.

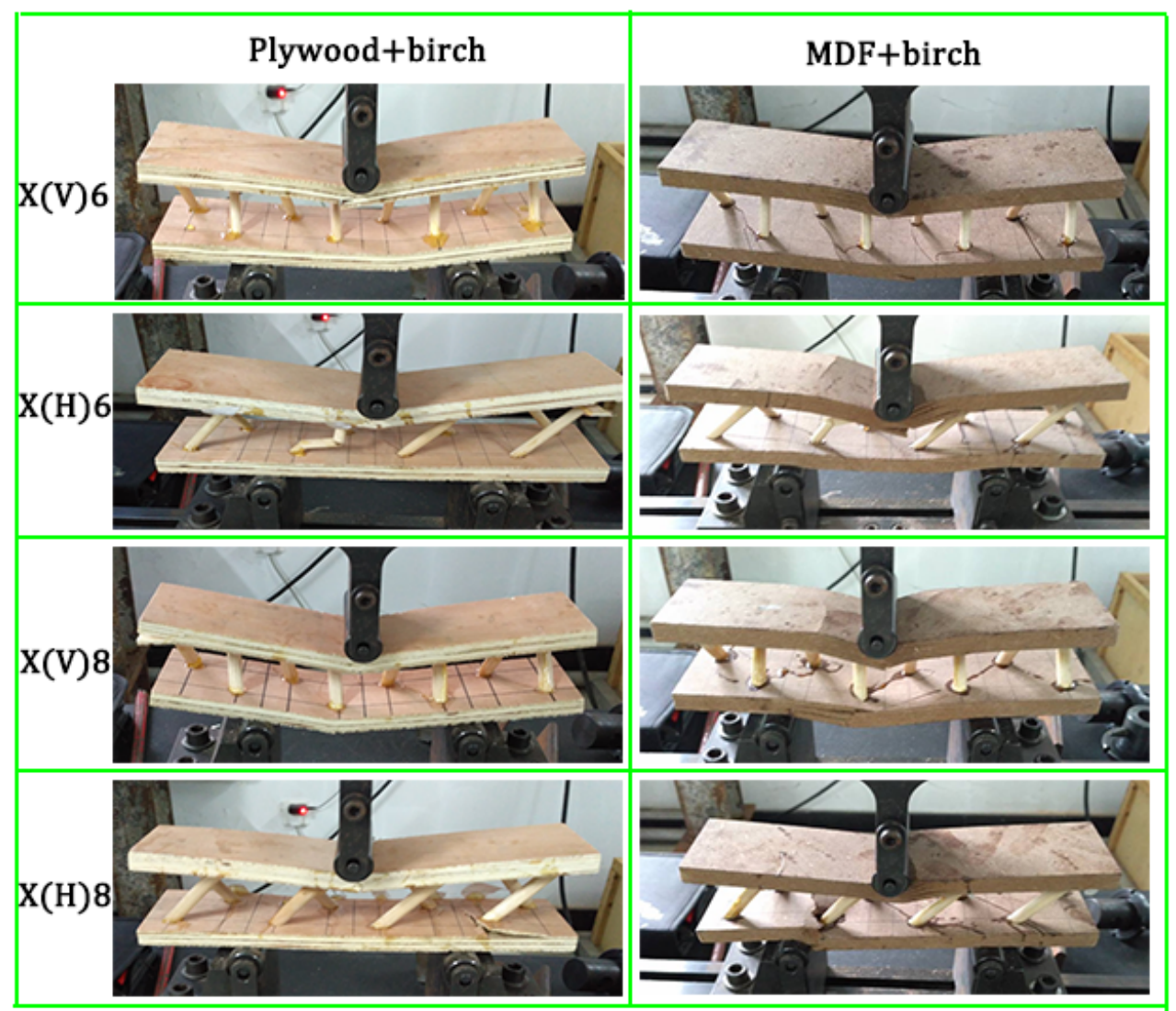

Fig. 10. Short beam shear failure modes of the two types of X-type lattice sandwich structures

For the combination of MDF and birch, the shear stress of the core of the X-type lattice sandwich structure is proportional to the diameter of the core (Fig. 11(a)). 
(a)

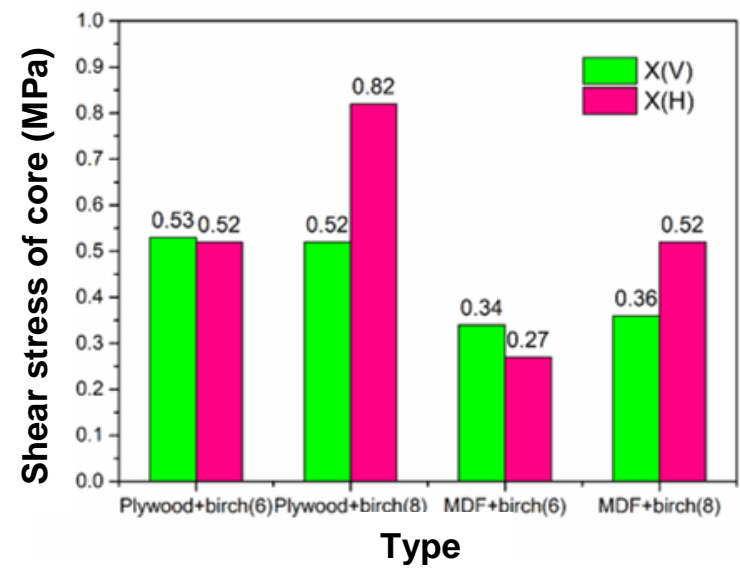

(b)

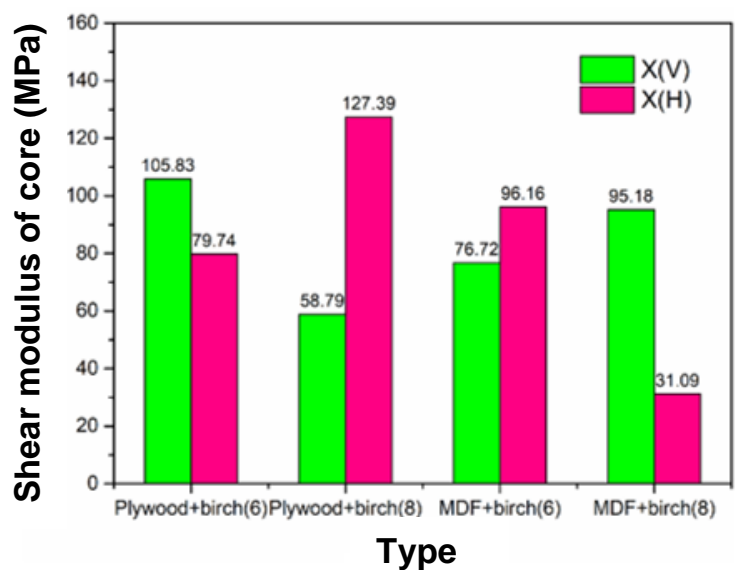

Fig. 11. (a) Shear stress of the core, (b) Shear modulus of the core of the two types of X-type lattice sandwich structures

However, the shear modulus of the core of the X-type lattice sandwich structure is not proportional to the diameter of the core (Fig. 11(b)). The shear modulus of the core of the $\mathrm{X}(\mathrm{V})$-type lattice sandwich structure with a core diameter of $8 \mathrm{~mm}$ is $206.14 \%$ larger than that of the $\mathrm{X}(\mathrm{H})$-type lattice sandwich structure. This is because the core direction of the $\mathrm{X}(\mathrm{H})$-type lattice sandwich structure is perpendicular to the particleboard direction, and cores are easily broken.

The shear stress and modulus of the core of the plywood and birch combination are generally larger than those of MDF and birch in the same configuration and the same core diameter. The failure mode of plywood and birch is delamination at both ends of the panel or core breakage, which indicates that the plywood and birch has better short beam shear properties than those of MDF and birch.

\section{Comparison of the Theoretical Prediction and Experimental Results}

The data shown in Table 4 reveal that the experimental results of compressive modulus for the X-type lattice sandwich structure was very different from those predicted by the theoretical analysis results, which may be due to the defects produced during the processing of the specimens. The theoretical predictions and experimental results of the compressive strength/modulus of plywood and birch were close when the core diameter was $6 \mathrm{~mm}$, as the failure mode of the structure was shear failure in the core. The core was broken, or a slip surface appeared, which followed the theoretical model.

Table 4. Theoretical Predictions and Experimental Results of the Compressive Strength/Modulus of the X-Type Lattice Sandwich Structure

\begin{tabular}{|c|c|c|c|c|c|}
\hline \multirow[b]{2}{*}{ Materials } & \multirow[b]{2}{*}{$\begin{array}{c}\text { Core } \\
\text { Diameter }\end{array}$} & \multicolumn{2}{|c|}{ Theoretical } & \multicolumn{2}{|c|}{ Experimental } \\
\hline & & $\begin{array}{c}\text { Strength } \\
(\mathrm{MPa})\end{array}$ & $\begin{array}{c}\text { Modulus } \\
(\mathrm{MPa})\end{array}$ & $\begin{array}{c}\text { Strength } \\
\text { (MPa) }\end{array}$ & $\begin{array}{c}\text { Modulus } \\
(\mathrm{MPa})\end{array}$ \\
\hline \multirow{2}{*}{ Plywood/birch } & $6 \mathrm{~mm}$ & 0.15 & 2.72 & 0.11 & 2.68 \\
\hline & $8 \mathrm{~mm}$ & 0.29 & 9.80 & 0.20 & 11.07 \\
\hline \multirow{2}{*}{ MDF/birch } & $6 \mathrm{~mm}$ & 0.18 & 2.72 & 0.19 & 4.05 \\
\hline & $8 \mathrm{~mm}$ & 0.15 & 9.80 & 0.33 & 7.26 \\
\hline
\end{tabular}


Table 5. Theoretical Predictions and Experimental Results of the Short Beam Shear Stress/Modulus of the X-Type Lattice Structure

\begin{tabular}{|c|c|c|c|c|c|c|}
\hline \multirow[b]{2}{*}{ Materials } & \multirow[b]{2}{*}{ Type } & \multirow[b]{2}{*}{$\begin{array}{c}\text { Core } \\
\text { Diameter }\end{array}$} & \multicolumn{2}{|c|}{ Theoretical } & \multicolumn{2}{|c|}{ Experimental } \\
\hline & & & $\begin{array}{l}\text { Stress } \\
(\mathrm{MPa})\end{array}$ & $\begin{array}{l}\text { Modulus } \\
\text { (MPa) }\end{array}$ & $\begin{array}{l}\text { Stress } \\
(\mathrm{MPa})\end{array}$ & $\begin{array}{c}\text { Modulus } \\
\text { (MPa) }\end{array}$ \\
\hline \multirow{4}{*}{ Plywood/birch } & \multirow[t]{2}{*}{$\mathrm{X}(\mathrm{V})$} & $6 \mathrm{~mm}$ & 0.46 & 75.05 & 0.53 & 105.83 \\
\hline & & $8 \mathrm{~mm}$ & 0.52 & 57.00 & 0.52 & 58.79 \\
\hline & \multirow[t]{2}{*}{$\mathrm{X}(\mathrm{H})$} & $6 \mathrm{~mm}$ & 0.47 & 72.03 & 0.52 & 79.74 \\
\hline & & $8 \mathrm{~mm}$ & 0.80 & 113.55 & 0.82 & 127.39 \\
\hline \multirow{4}{*}{ MDF/birch } & \multirow[t]{2}{*}{$\mathrm{X}(\mathrm{V})$} & $6 \mathrm{~mm}$ & 0.32 & 74.71 & 0.34 & 76.72 \\
\hline & & $8 \mathrm{~mm}$ & 0.35 & 91.52 & 0.36 & 95.18 \\
\hline & \multirow[t]{2}{*}{$\mathrm{X}(\mathrm{H})$} & $6 \mathrm{~mm}$ & 0.27 & 95.54 & 0.27 & 96.16 \\
\hline & & $8 \mathrm{~mm}$ & 0.52 & 30.63 & 0.52 & 31.09 \\
\hline
\end{tabular}

The data presented in Table 5 reveal that the experimental results of the short beam shear stress/modulus for the X-type lattice structure with two combinations were lower than those predicted by the theoretical analysis results. However, the experimental results of short beam shear modulus of the $\mathrm{X}(\mathrm{H})$-type lattice sandwich structure with a core diameter of $6 \mathrm{~mm}$ were $41.01 \%$ larger than those of the $\mathrm{X}(\mathrm{V})$-type lattice sandwich structure. This may be because the upper panel was seriously damaged at the loading point and the core was broken. Thus, the theoretically predicted values were very different from the experimental values. The combination of plywood and birch was more suitable for the short beam shear theoretical model. The plywood ends were layered and the contact point between the core and panel was damaged, which followed the theoretical model.

\section{CONCLUSIONS}

1. The failure mode of the plywood and birch combination was core shear failure and broken or sliding cores, while the failure mode of the MDF and birch combination was mainly shear failure of the cores at the two ends. The core diameter had a greater impact on the compressive property of the wood-based X-type lattice sandwich structure. With the same core diameter, MDF and birch had better compression properties than the structure of plywood and birch in which load capacity, compressive strength, and compression modulus were generally high.

2. By comparing the specific strength of the two combinations, it was found that the specific strength of plywood and birch was larger overall, which followed characteristics of light weight and high strength.

3. The shear stress and modulus of the core of plywood and birch was generally larger than MDF and birch in the same configuration and the same core diameter. The failure mode of plywood and birch was delamination at both ends of the panel or core breakage, which indicated that it had better short beam shear properties than MDF and birch.

4. The theoretical models are suitable to account for the compressive and short beam shear properties of the combination of plywood and birch. The compressive failure mode of the structure was shear failure in the core. The short beam shear failure mode was involved with the ends of panel. The contact point between the core and panel was damaged, which followed the theoretical model. 


\section{ACKNOWLEDGEMENTS}

The authors are grateful for the support from the National Natural Science Foundation of China (31470581), and the Fundamental Research Funds for the Central Universities (2572016EBJ1).

\section{REFERENCES CITED}

ASTM C365/C365M-16 (2016). "Standard test method for flatwise compressive properties of sandwich cores," ASTM International, West Conshohocken, USA.

ASTM C393/C393M-16 (2016). "Standard test method for core shear properties of sandwich constructions by beam flexure," ASTM International, West Conshohocken, USA.

Ashby, M. F. (2001). "Drivers for material development in the $21^{\text {st }}$ century," Prog. Mater. Sci. 46(3-4), 191-199. DOI: 10.1016/s0079-6425(00)00014-1

Ashby, M. F., Evans, A., Fleck, N., and Gibson, L. J. (2000). "Metal foams: A design guide," Mater Design 23(1), 119. DOI: 10.1016/S0261-3069(01)00049-8

Bunyawanichakul, P., Castanié, B., and Barrau, J. J. (2008). "Non-linear finite element analysis of inserts in composite sandwich structures," Compos. Part B-Eng. 39, 10771092. DOI: 10.1016/j.compositesb.2008.05.004

Deshpande, V. S., Ashby, M. F., and Fleck, N. A. (2001). "Foam topology: bending versus stretching dominated architectures," Acta. Materialia 49, 1035-1040. DOI: 10.1016/S1359-6454(00)00379-7

Deshpande, V. S., Fleck, N. A., and Ashby, M. F. (2001). "Effective properties of the octet-truss lattice material," J. Mech. Phys. Solids 49, 1747-1769.

DOI: 10.1016/S0022-5096(01)00010-2

Evans, A. G. (2001). "Lightweight materials and structures," Mrs. Bull. 26, 790-797. DOI: $10.1557 / \mathrm{mrs} 2001.206$

Garg, A., and Chalak, H. D. (2019). "A review on analysis of laminated composite and sandwich structures under hygrothermal conditions," Thin. Wall. Struct. 142, 205226.

Giancaspro, J., Balaguru, P. N., and Lyon, R. E. (2006). "Use of inorganic polymer to improve the fire response of balsa sandwich structures," J. Mater. Civ. Eng. 18(3), 390-397. DOI: 10.1061/(ASCE)0899-1561(2006)18:3(390)

Healy, S., Mahon, J. M., and Gerald, U. F. (2018). "Seeing the wood for the trees: towards improved quantification of glial cells in central nervous system tissue," Neural Regen Res. 9, 1520-1523. DOI: 10.4103/1673-5374.235222

Hu, S. Y., Guan, X., Guo, M. H., and Wang, J. M. (2018). "Environmental load of solid wood floor production from larch grown at different planting densities based on a life cycle assessment," J. Forestry Res. 5, 1443-1448. DOI: 10.1007/s11676-017-0529-x

Irle, M., Privat, F., Couret, L., Belloncle, C., Déroubaix, G., Bonnin, E., and Cathala, B. (2019). "Advanced recycling of post-consumer solid wood and MDF," Wood Mater. Sci. Eng. 14, 19-23. DOI: 10.1080/17480272.2018.1427144

Jamalirad, L., Aminian, H., and Hedjazi, S. (2019). "Exploring the potential of milkweed stalk in wood plastic manufacture," J. Nat. Fibers 16, 77-87. DOI:

10.1080/15440478.2017.1401507 
Jiang, W., Chen, H., Gong, J. M., and Tu, S. T. (2011). "Numerical modelling and nanoindentation experiment to study the brazed residual stresses in an X-type lattice truss sandwich structure," Mat. Sci. Eng. A-Struct. 528, 4715-4722. DOI: 10.1016/j.msea.2011.02.073

Jin, M. M., Hu, Y. C., and Wang, B. (2015). "Compressive and bending behaviors of wood-based two-dimensional lattice truss core sandwich structures," Compos. Struct. 124, 337-344. DOI: 10.1016/j.compstruct.2015.01.033

Karam, G. N., Member, A., and Gibson, L. J. (1994). "Evaluation of commercial woodcement composites for sandwich-panel facing," J. Mater. Civ. Eng. 6(1), 100-116. DOI: 10.1061/(ASCE)0899-1561(1994)6:1(100)

Kržišnik, D., Brischke, C., Lesar, B., Thaler, N., and Humar, M. (2019). "Performance of wood in the Franja partisan hospital," Wood Mater. Sci. Eng. 14, 24-32. DOI: 10.1080/17480272.2018.1438512

Li, S., Zheng, T. T., Li, Q., Hu, Y. C., and Wang, B. (2019). "Flexural and energy absorption properties of natural-fiber reinforced composites with a novel fabrication technique," Composite. Commun. 16, 124-131.

Li, K., Gao, X. L., and Roy, A. K. (2003). "Micromechanics model for three-dimensional open-cell foams using a tetrakaidecahedral unit cell and Castigliano's second theorem," Compos. Sci. Technol. 63(12), 1769-1781. DOI: 10.1016/S02663538(03)00117-9

Li, S., Qin, J. K., Li, C. C., Feng, Y. X., Zhao, X., and Hu, Y. C. (2018). “Optimization and compressive behavior of composite 2-D lattice structure," Mech. Adv. Mater. Struct. 1-10. DOI: 10.1080/15376494.2018.1504361

Li, S., Qin, J. K., Wang, B., Zheng, T. T., and Hu, Y. C. (2019). "Design and compressive behavior of a photosensitive resin-based 2-D lattice structure with variable cross-section core," Polymers 11, 186. DOI: 10.3390/polym11010186

Liu, J., Chen, T. T., Wen, G. L., Qing, Q. X., Sedaghati, R., and Xie, Y. M. (2019). “On sound insulation of pyramidal lattice sandwich structure," Compos. Struct. 208, 385394. DOI: 10.1016/j.compstruct.2018.10.013

Liu, J. Y., Qiao, W. F., Liu, J. X., Xie, D., Zhou, Z. G., Wu, L. Z., and Ma, L. (2015). "High temperature indentation behaviors of carbon fiber composite pyramidal truss structures," Compos. Struct. 131, 266-272. DOI: 10.1016/j.compstruct.2015.04.056

Mahmut, E. (2014). "Testing and acceptance criteria for fiber-reinforced composite grid connectors used in concrete sandwich panels," J. Mater. Civ. Eng. 26(6). DOI: 10.1061/(ASCE)MT.1943-5533.0000915

Manalo, A. C. (2013). "Behaviour of fibre composite sandwich structures under short and asymmetrical beam shear tests," Compos. Struct. 99, 339-349. DOI:

10.1016/j.compstruct.2012.12.010

Mathieson, H., and Fam, A. (2015). "Effect of internal ribs on fatigue performance of sandwich panels with GFRP skins and polyurethane foam core," J. Mater. Civ. Eng. 27(2). DOI: 10.1061/(ASCE)MT.1943-5533.0000992

Munir, M. T., Belloncle, C., Irle, M., and Federighi, M. (2019). "Wood-based litter in poultry production: A review," World Poultry Sci. J. 75, 5-16. DOI: $10.1017 / \mathrm{S} 0043933918000909$ 
Pandit, M. K., Sheikh, A. H., and Singh, B. N. (2008). "An improved higher order zigzag theory for the static analysis of laminated sandwich plate with soft core," Finite Elem. Anal. Des. 44, 602-610. DOI: 10.1016/j.finel.2008.02.001

Profft, I., Mund, M., Weber, G. E., Weller, E., and Schulze, E. D. (2009). "Forest management and carbon sequestration in wood products," Eur. J. Forest Res. 128(4), 399-413. DOI: 10.1007/s10342-009-0283-5

Qin, J. K., Zheng, T. T., Li, S., Cheng, Y. P., Xu, Q. Y., Ye, G. Y., and Hu, Y. C. (2019). "Core configuration and panel reinforcement affect compression properties of woodbased 2-D straight column lattice truss sandwich structure," Eur. J. Wood and Wood Prod. 77(4), 539-546. DOI: 10.1007/s00107-019-01410-1

Wang, B., Wu, L. Z., Jin, X., Du, S.Y., Sun, Y. G., and Ma, L. (2010). "Experimental investigation of 3D sandwich structure with core reinforced by composite columns," Mater. Design. 31(1), 158-165. DOI: 10.1016/j.matdes.2009.06.039

Wang, B., Wu, L.Z., Ma, L., and Feng, J. C. (2011). "Low-velocity impact characteristics and residual tensile strength of carbon fiber composite lattice core sandwich structures," Compos. Part B-Eng. 42(4), 891-897. DOI: 10.1016/j.compositesb.2011.01.007

Wang, B., Xiong, J., Wang, X. J., Ma, L., Zhang, G. Q., Wu, L. Z., and Feng, J. C. (2013). "Energy absorption efficiency of carbon fiber reinforced polymer laminates under high velocity impact," Mater. Design 50, 140-148. DOI: 10.1016/j.matdes.2013.01.046

Wang, B., Zhang, G. Q., He, Q. L., Ma, L., Wu, L. Z., and Feng, J. C. (2014). "Mechanical behavior of carbon fiber reinforced polymer composite sandwich panels with 2-D lattice truss cores," Mater. Design 55, 591-596. DOI: 10.1016/j.matdes.2013.10.025

Wang, B., Zhang, G. Q., Wang, S. X., Ma, L., and Wu, L. Z. (2014). "High velocity impact response of composite lattice core sandwich structures," Appl. Compos. Mater. 21(2), 377-389. DOI: 10.1007/s10443-013-9345-4

Wang, B., Hu, J., Li, Y., Yao, Y., Wang, S., and Ma, L. (2018). "Mechanical properties and failure behavior of the sandwich structures with carbon fiber-reinforced X-type lattice truss core," Compos. Struct. 185, 619-633. DOI: 10.1016/j.compstruct.2017.11.066

Way, D., Sinha, A., Kamke, F. A., and Fujii, J. S. (2016). "Evaluation of a wood-strand molded core sandwich panel," J. Mater. Civ. Eng. 28(9). DOI:

10.1061/(ASCE)MT.1943-5533.0001589

$\mathrm{Xu}$, J., Wu, T., Sun, W., and Peng, C. (2017). "Characterization of insulation performance, post stability, and foaming process of rigid polyurethane sandwich panel for cold storage warehouse," J. Mater. Civ. Eng. 29(9).

DOI: 10.1061/(ASCE)MT.1943-5533.0001984

Yin, S., Wu, L. Z., Ma, L., and Nutt, S. (2011). "Pyramidal lattice sandwich structures with hollow composite trusses," Compos. Struct. 93(12), 3104-3111. DOI: 10.1016/j.compstruct.2011.06.025

Yin, S., Wu, L. Z., Ma, L., and Nutt, S. (2012). "Hybrid truss concepts for carbon fiber composite pyramidal lattice structures," Compos. Part B-Eng. 43(4), 1749-1755. DOI: 10.1016/j.compositesb.2012.01.033 
Yin, S., Wu, L. Z., and Nutt, S. (2013). "Stretch-bend-hybrid hierarchical composite pyramidal lattice cores," Compos. Struct. 98(3), 153-159. DOI:

10.1016/j.compstruct.2012.11.004

Article submitted: September 23, 2019; Peer review completed: December 21, 2019; Revised version received: January 8, 2020; Accepted: January 9, 2020; Published:

January 29, 2020.

DOI: $10.15376 /$ biores.15.1.1927-1944 